\title{
Terminal cancer in Northeast India: an analytical study on its rapid growth, causes, and solutions
}

\author{
Suantak Demkhosei Vaiphei $\odot$, Devendra Singh Sisodia $\odot$
}

Department of Psychology, Bhupal Noble's University, Udaipur, India

\begin{abstract}
The underlying aim of the study is to investigate the reasons behinds the rapid growths of cancer populations and the cancer mortality rates in the Northeastern States of the country. The current study is an analytical study on the collected data and reports of the following reliable sources: The Population-Based Cancer Registries' Data of the Central and State Governments, the data from National Cancer Registry and Regional Cancer Centers, National Family Health Survey of India (NFHS-3), National Institute of Cancer Prevention and Research, and Indian Council of Medical Research. The study will be specific to the reasons behind the rapid growths, causes, and solutions in the Northeastern regions of the country. The study also utilized the available journals database, along with World Health Organization database. The researcher also access to the government's data and hospitals documents on cancer statistics and their reports. By eliminating the usages of tobacco, cigarettes, chewing, and bitternuts with hygenic environment, the rates of oral lip, breast, mouth, cervical, head and neck, and the nasopharyngeal cancer can successfully be reduces into at least $40-50 \%$ in Northeast region, as per the researcher findings. The urgent need of the regions is to develop social awareness on the causes of cancer. Gearing up for health awareness and strengthening the health care team at the community level by addressing the cancer preventive measures in the Northeast region will effectively decreases the growing cancerpopulations of cancer/terminal illness.

Keywords: Cancer, terminal illness, awareness, terminal deaths, early detection
\end{abstract}

$\mathrm{T}$ he increasing of the modern technologies requires the setting up of multiple factories and industries that produce smokes and chemicals, which polluted the air, water, and the environment resulting in putting lives in dreaded conditions. In fact, the coming of the modern era and the modern lifestyle gives birth to numerous deadly diseases like cancer and its related diseases, which increasingly takes the lives of many in the Northeast regions of the country. The cold-blooded killer 'cancer' becomes the major public health concern in Northeast region in particular and India as a whole in India today. Among all the prob- lems existed across the world, the problems or the issues associated with cancer or terminal illness becomes the worldwide phenomenon that produces several unwanted worst experiences. Human polluting the water, soil, and the air continued and the global burden of cancer affected populations rapidly increasing year after year. Unfortunately, the Northeast States of India turns out to be the world most densely cancer populated regions. The reason behind the rapidly increasing of cancer illness and its mortality rates in these regions were generally people lack of awareness on cancerous factors, no proper preventive measures, 
and the late detection of the symptoms at the advanced stages when cure is not possible. Thus, concerning the helplessness conditions of the people of Northeast in general, the current analytical study has been forms with an aim to spread awareness on the cold-blooded killer cancer. The study focus mainly on the current cancer situations and the underlying causes of cancer in the North Eastern regions of the country. The study also includes the essential preventive strategies and the treatment policy when it comes to its terminal stages.

\section{CURRENT SITUATIONS OF ILLNESS IN NORTHEAST INDIA}

CANCER

In the definitions of World Health Organization, cancer or terminal illness is the uncontrolled growth of deadly cells with unstoppable spreads, which destroys every portion of human body organs one after another. Once the deadly cells increase and affected the patient's startlosing the functioning of his/her body sites that usually leads to a paralyses condition. These deadly cancer cells expanded through invading the surrounding tissues and spreads to other parts of the body by metastasis leading to 8.2 million global deaths a year at present. In which India becomes the world top contributor to cancer mortality rates with around 556,400 terminal deaths per year as per World Health Organization [1]. The modern India turn out to be a cancer hub with 2.5 million cancer-affected people (Table 1), which would be expect to increases by $50 \%$ in 2020, if no immediate action plan had been done by the governmental and non-governmental agencies. A premature death through non-communicable diseases is the leading causes of deaths in India like cardiovascular ailments, chronic respiratory problems, and diabetes [2]. Unfortunately, the Northeastern regions become the largest contributors to cancer illness and its mortality rates in the country.
The cervical and stomach cancer symptoms populations in Mizoram alone is equal with the total numbers of cancer affected populations of Japan, and is the highest cancer populated region in the world [3]. At present, Aizawl in the State of Mizoram and Papumpare District of Arunachal Pradesh has the highest age adjusted cancer incidences in the country. In which 271 men in 100,000 populations in Aizawl were with Cancer illness, and 249 cancer patients in 100,000 populations in Papumare town of Arunachal Pradesh. The third highest cancer population in the country is in Karum district of Assam with 206 cancer patients in 100,000 populations [4]. In Mizoram and Tripura, the cervical cancer is the leading cancer symptoms, while in the State of Nagaland and Meghalaya, tongue, mouth, stomach, and gall bladder were the leading cancer symptoms. While in Manipur cervical, oral, lip, mouth, pharyngeal, head, and neck cancer were visible largely affecting people. Table 2 shows the five most common deadly cancer symptoms, its causes, and the numbers of terminal deaths in a year in India as a whole.

Looking at the present conditions, it is visible that Northeast in particular and India as a whole is fighting with the cold-blooded killer "Terminal Illness" in the most unsuccessful ways. Moreover, India at present is in critical conditions with rapid increasing of one-lakh cancer populations and with the minimal cancer care center, which is around only 300 regional cancer care centers thatare not enough even to treats the one thirds of the cancer populations. The India today had only 1000 oncologists, which is in the ratio of 1:2000 one oncologist per two thousand cancer patients. This constituted the underlying reason why modern India turned into a cancer hub and the fighting will continues as the numbers of affected patient's raises up every year $[5,6]$. The following statistic is form to explain the details about of the current cancer status of India today:

In the latest statistical report of NICPR at present

Table 1. Current cancer statistic in India

\begin{tabular}{ccccccc}
\hline $\begin{array}{c}\text { No. of } \\
\text { cancer } \\
\text { affected }\end{array}$ & $\begin{array}{c}\text { Yearly } \\
\text { cancer } \\
\text { registration }\end{array}$ & $\begin{array}{c}\text { No. of } \\
\text { deaths } \\
\text { in a year }\end{array}$ & $\begin{array}{c}\text { Common } \\
\text { age of death } \\
\text { (39-60 years) }\end{array}$ & Women & Men & Percentage \\
\hline 2.5 million & 7 Lakh & 556,400 & 395,400 & 195,300 & 200,100 & $71 \%$ \\
\hline
\end{tabular}

Adapted from NICPR statistical report on August 23, 2018. 
Table 2. The five common cancer symptoms in Northeast and yearly terminal deaths [4]

\begin{tabular}{lccc}
\hline & Cancer symptoms & $\begin{array}{c}\text { Numbers of deaths } \\
\text { per year }\end{array}$ & Main causes \\
\hline 1 & Head \& neck cancer & 575,000 & Alcohol, tobacco, and cigarettes \\
2 & Breast cancer & 522,000 & Unhealthy lifestyle, genetic, and alcohol \\
3 & Gall bladder cancer & 230,000 & $\begin{array}{c}\text { Unhealthy lifestyle, genetic, and poor } \\
\text { prevention }\end{array}$ \\
4 & Cervical cancer & 67,477 & $\begin{array}{c}\text { Human papilloma virus (HPV), birth control } \\
\text { pills, smoking, and unhealthy sex }\end{array}$ \\
\hline 5 & Oral cancer & 45,800 & $\begin{array}{c}\text { Smoking, tobacco, alcohol, HPV, sunlight, and } \\
\text { weak immune system }\end{array}$ \\
\hline
\end{tabular}

one woman dies of cervical cancer every 8 minutes and for every newly diagnosis with breast cancer one out of two women dies in India today. Moreover, around 2,500 died per day due to the consumptions of tobacco and bitternut. While smoking, which is the most common practices in India cause 1 in 5 death amongst men and 1 in 20 death amongst women, which constituted around 930,000 deaths in 2010 mainly because of smoking related issues in the country. In which the most productive age period could be highlights in the ages between $30-60$ years [7], which need a special consideration and these ages grouped need to be targeted the most.

\section{UNDERLYING CAUSES OF CANCER AND ITS DEADLY SYMPTOMS}

The main cause of cancer is through the internal factors (inherited mutations, hormones, and immunes conditions) and external/ environment factors (tobacco, insufficient diet, unhealthy food, organism, and chemical with radiations) (Table 3 ). Among all these components for the causes of cancer and its deadly symptoms, there is a closed link between unhealthy food and insufficient diets with cancer disease as observed by many experts [2]. Unhealthy lifestyles with alcohol and smoking are the second most common cancerous factors leading to chronic disease, cardiovascular, lung, kidney, throat, esophagus, and breast cancer. The third common factor for the causes of cancer is visible in excessive consumptions of red meats and fish leading to heart and breast cancer [8]. Moreover, looking at the context of Northeast India at present, all the three main cancerous factors are the most common practices of the people like eating tobacco, unhealthy lifestyle,

\section{Table 3. Cancerous factors in Northeast India}

\begin{tabular}{ccccc}
\hline \multicolumn{4}{c}{ Factors for the causes of cancer and it's deadly symptoms } & \\
\hline Tobacco products & $\begin{array}{c}\text { Excessive alcohol } \\
\text { uses }\end{array}$ & Insufficient diets & $\begin{array}{c}\text { Excessive } \\
\text { cholesterols }\end{array}$ & Physical inactivity \\
$\begin{array}{c}\text { Ultraviolet } \\
\text { radiation }\end{array}$ & Virus \& bacteria's & $\begin{array}{c}\text { Ionizing radiation/ } \\
\text { waves or particles }\end{array}$ & $\begin{array}{c}\text { Uses of pesticides } \\
\text { in cultivations }\end{array}$ & $\begin{array}{c}\text { Excessive medical } \\
\text { drugs }\end{array}$ \\
$\begin{array}{c}\text { Solvents or } \\
\text { unhealthy liquids } \\
\text { components }\end{array}$ & $\begin{array}{c}\text { Fibers or any } \\
\text { mineral substances }\end{array}$ & $\begin{array}{c}\text { Fine particles, dust \& contaminants } \\
\text { environment }\end{array}$ & $\begin{array}{c}\text { Dioxins highly } \\
\text { toxic components }\end{array}$ \\
$\begin{array}{c}\text { Polycyclic } \\
\text { aromatic } \\
\text { hydrocarbon } \\
\text { PAHs }\end{array}$ & $\begin{array}{c}\text { Metals or coated } \\
\text { with metals }\end{array}$ & $\begin{array}{c}\text { Diesel exhaust } \\
\text { particles }\end{array}$ & Toxin from fungi & $\begin{array}{c}\text { Smoking \& } \\
\text { hookahs' }\end{array}$ \\
$\begin{array}{c}\text { Vinyl chloride } \\
\text { and benzedrine }\end{array}$ & Excessive meat's & $\begin{array}{c}\text { Unhealthy } \\
\text { drinking water }\end{array}$ & $\begin{array}{c}\text { Chewing of } \\
\text { bitternuts }\end{array}$ & Junk food \\
\hline
\end{tabular}


excessive consumptions of meats of any kind, and drinking alcohol to the maximum, which resulted in turning these tiny regions into a cancer hub. At present as per the National Tobacco Control Programme, Manipur has the highest age adjusted tobacco consumption in India, in which every second men and every third women were addicted with tobacco. Thus, becoming the highest burden of tobacco related cancer illness in the country like heart attack, lung diseases, and stroke, etc. The uses of tobacco causes $100 \%$ poor oral health with $90 \%$ of mouth cancer, $80 \%$ of lung cancer, $50 \%$ of all human cancers, $70 \%$ of lung diseases, and $60 \%$ of heart attacks. Unfortunately, Manipur stood in the world top for lung cancer, especially among the female population mainly due to the uses of tobacco, smoking, and the smoke produces by firewood in cooking [9]. As per the Global Adult Tobacco Survey, 54\% of people in Manipur are addicted with tobacco of which $66.6 \%$ men and $41.8 \%$ women excessively use tobacco, resulting in causing premature terminal deaths to 100,000 people in a year $[9,10]$.

Another reason for the Northeast being the top cancer populated in the country is mainly due to people unawareness of cancerous components, its preventive measures, and the treatment policy. Due to the lack of awareness, people in these regions detect their cancer symptoms only when it comes to terminal stages (third or fourth stages), which is in the condition of impossible to cure. Late detection of cancer symptoms and late cancer diagnosis becomes the underlying reasons for failing to cure $80 \%$ of cancer illness in India today. However, early detections of the symptoms in its first stage there is $80 \%$ chances to cure. On the other hand, undergoing cancer diagnosis in the second stages could possibly have $60 \%$, chances for cure, and in the third stage the cure possibility rates reduces down to $30 \%$, but with the possibility of stage four of cancer within a short period of time. However, in the fourth stage, which is the terminal stage there is no chances to cure, rather to live with the pain symptoms for maximum life spends of 5-7 years [5, 6].

The causes of stomach and cervical cancer symptoms in Mizoram were mainly due to the consumptions of water filtrate tobacco "Tuibur," excessive drinking of alcohol, cigarette smoking, and bitternuts. While in Manipur, lung and oral cancer hugely affect the men and women populations, the reason being excessive uses of tobacco, smoking, hookah, and the consumption of local made alcohol. Another prevailing cancer symptom in Manipur is nasopharyngeal cancer, which is a malignant cells disease form in the tissues of the nasopharynx. The nasopharyngeal cancer (NPC) is the rarest type of cancer around the world; accept in the South East Asia, North Africa, and Arctic. The NPC is claims to be a Chinese origin, which is largely affecting the Northeast Indian states of Nagaland, Manipur, Mizoram, and to some extend to Meghalaya. The state of Nagaland has the highest age adjusted with $19.5 / 100,000$, followed by the state of Manipur. The nasopharyngeal cancer is mainly causes by excessive eating of meat, fish, salted fish, uses of firewood in the house and other environmental related factors like the eating of bitternuts (Kuwa or Komkuwa) with or without tobacco products. Mostly the women populations in Manipur were mainly affects with nasopharyngeal cancer comparing to men. Moreover, within 15-20 years the nasopharyngeal affected women populations in Manipur will be increasing, if the uses of tobacco, bitternuts, and the uses of firewood in cooking are not being under-controlled [3, 11]. The table below will clearly shows the various factors that are responsible for the causes of cancer as a whole:

Moreover, apart from food habits, the population explosion, rapid industrialization, and genetics, which include mutations, hormonal and lack of immunity are also responsible for the rapid growth of terminal illness in the these regions. If proper awareness had not given to the people of Northeast, there is a possibility of increasing cancer populations to $19 \%$ in the next five years. In which women have more chances of affected with cancers than men in India, as per the findings of many. Moreover, the mortality rate of cancers in India is visible higher among the illiterate people groups in the rural areas of the country than the educated, and the maximum deaths in India are mainly due to poor prevention strategies and no proper diagnosis as a whole [12].

According to the latest NICRP reports, 122,844 women are diagnoses with cervical cancer every year out of which 67,477 women died from cervical cancer per year. In a population of 432.2 million women in India at present, those women who are at the age of 
15 and above and or between $15-40$ years are at risk of developing cervical cancer in India. The health scientists on the other hand, were not able to identify the processes of how the risk factors like genetic, hormonal, and environment factors works together to cause normal cells to become cancerous tumor for the cancer symptoms. Thus, cancer becomes the leading causes of deaths in India, with 2.5 million cancer populations, with 1 million cancer patients added every single year and it could be predicts that the numbers of cancer patients by 2025 would be increases by five fold in India [7, 8]. The rapid increasing rates of cancer in the country are mainly due to lifestyle risk factors like uses of tobacco, alcohol, low fiber in diet, increasing body weight, minimal physical activities, and the reproductive risk factors in regards to age at first pregnancy, and higher numbers of children breastfeeding's. Out of many cancer mortalities, the two leading deaths are from cervical cancer (HPV), hepatitis C (liver), and gastric H. Pylori (stomach). Moreover, in Northeast India genetic and environmental factors combine in making the region as the highest cancer populated in the country, the people on the other hand were highly unaware of the cancerous factors and its preventive measures [13].

\section{SOLUTIONS AND PREVENTIVE MEASURES: TRADITIONAL APPROACH}

Terminal deaths is the top causes of Death in India, and the Northeastern states of the country becomes the top contributors to cancer illness and its mortality rates. In the 2000, India was in Seventh position among the world cancer populated country, however the rapid increasing of cancer populations in the Northeast States like Mizoram, Arunachal, Assam, Manipur, Nagaland, and Meghalaya in 2007-2018 India successfully stood in world top cancer populated country, and the numbers of effected populations is visible increasing with 100,000 in a year. Looking at the cancerous factors only $5-10 \%$ the cancer is from genetics, in which the other $90-95 \%$ of the cancer and its related diseases are from hormonal and environment factors. Moreover, the $90 \%$ of the cancer and its related diseases can be effectively prevents through proper medical interventions in its early stages. Another $10 \%$ genetic cancerous symptoms can also be cure through early detection and immediate diagnosis. In short, cancer of any types is curable if detected in its early stages and through proper preventive measures [14]. The followings are the qualitative preventive measures in order to control the rapid growths of cancer in the Northeast Regions of the country [2, 8, 14, 15]: (1) Regular medical checked-up, though being in a healthy condition, negligees of regular medical checked-up is visible as the underlying reason for the rapid growths of cancer in Northeast in the past ten years; (2) Educating people with proper awareness strategies, offer effective public health concerned in the school, Church meetings, or organizing a social meeting for spreading cancer awareness; (3) Early detection of the symptom and early medical intervention, because when it comes to third and fourth stages there is no possibility for cure; (4) Public awareness on active physical activities, exercise at least for 30 minutes per day, the healthier a person is the cells in the body effectively fights against the invader virus and bacteria's. Regular exercise prevents oneself from colon and breast cancer too; (5) Minimizing the uses of alcohol products, smoking, tobacco, and chewing of bitternut products, which will minimized the risk of having lung, kidney, throat, esophagus, and breast cancer. It is better to develop a moderate ways of consuming with 2-3 glass per day, which will keep oneself away from heart attacked; (6) Immunization against hepatitis B virus to the infants of one to sixth months old without failed. Neglecting medical treatment in hepatitis B \& C can causes chronic illness and liver cancer; (7) Developing healthy and safe sexual practices to avoid cancer genesis, unhealthy sexual practices can give birth to cancer cells; (8) Avoiding obesities, as being grossly fat or overweight have negative effects on health; (9) Developing healthy diets, a healthy diets has scientifically proven with numerous health benefits and reducing the risk from chronic diseases; (10) Reducing occupational and environmental exposures, as excessive exposures to chemical and its related heavy metals produces ill health. It also effected for the future offspring and produces toxicity; (11) Avoiding excessive consumption of red meats, salt and long preserved food. High consumptions of red meat, salt and preserved food leads to diabetes, breast cancer, and obesity; (12) Developing the habits of 
eating fruits regularly, most fruits are less in calories, sodium, and fats. Fruits are the sources of essential nutrients like potassium, dietary fibers, vitamin $\mathrm{C}$, and foliate (folic acid), which prevents deficiency, birth defect, and helps a person to growth with healthy blood pressure; (13) In order to have fair skins some avoid exposing to sunlight, wearing protective clothing during $10 \mathrm{am}-4 \mathrm{pm}$ and the excessive uses of sunscreen cream need to be avoid. Avoiding of exposing to sun or UV resulted in many women diagnoses with skin cancer. On the other hand, excessive exposing to sunlight or UV ray is also dangerous, especially for those having genetic cancerous symptoms; and (14) Immediate medical intervention on virus and bacterial infections, otherwise the bacteria diseases virus cells usually hide inside the cells and turning out to be a terminal virus. The increasing industrializations and urbanizations are visible as the two factors leading to new lifestyle of many Indians, which resulting in increasing the cancer affected populations in the country. Concerning the current polluted environment the burden of cancer incidences will gradually keep on increasing, as majorities of the Indians were not aware of cancerous preventive measures. The only ways to prevent the Indian men and women from the rapid growths of cancer and its deadly symptoms is to detect the symptoms at the early stages with immediate medical interventions. It is also important to prevent the water and the environment from polluted by industries and chemicals. However, it can only be possible only if the men and women in the rural areas were being educated on cancer awareness like preventive measures, and overall treatment policies, which needs multiple efforts from the government agencies and other nongovernmental agencies. Through such awareness programs, men and women should realize the risk factor and to identify the symptom through screening by physical examination or by self-cancerous symptom examination, in which if the rick substances where found than certain carcinogenic substances need to be reduces or eliminated. Moreover, there are over 85,000 synthetic chemicals that were easily available in the market of the country today like cosmetic items to flame-retardants, plasticizers in water bottles to pesticides in fruits and vegetables' etc. In the findings of the researcher, $80 \%$ of the cancer patients in the country were associated with environment factors like exposes to contaminants, unhealthy lifestyle, food, and exposing to ionizing radiations. In the urban areas, the cleaning of contaminated drainages without any proper preventive measures, polluting the river to the maximum with many forms of chemical and eating those fishes from the river produces several cancerous symptoms. The using of polluted water from the factories or industries for agricultural farming also produces several cancerous components leading in rapid increasing of cancer populations through consuming theses agricultural products $[2,12,14,16]$. Thus, maintaining healthy environment, healthy lifestyle, healthy food, proper diets, daily exercise, staying away from tobacco, and smoking, with decreasing alcohol consumptions can decreases the rates of canceraffected populations in the Northeast India. Moreover, the common practices in the Northeast villages of using of the water, which were uses in deeping the hot metal or iron in the blacksmith for washing hand and leg need to be avoided, as it contains the component that is cancerous.

\section{CANCER TREATMENT POLICY AND TERMINAL DIAGNOSIS}

The World Health Organization proposed that the cancer patients need immediate access to the modern equipments like; 3D Conformal Radiation Therapy, Intensely Modulated and Therapy (IMRT), Image Guided Radiation (IGRT). the VMAT and Rapid ArcVolumetric Modulated Arc Therapy (VMAT), Low Dose Rate Brachyntherapy (LDR), High Dose Rate Brachyntherapy (HRD), Deep Inspiration Breath Hold (using the goggles or snorkel technique), and Stereotactic Radiation Therapy [17[. However, in most of the cancer care centers in the North East regions of the country, the modern instruments for cancer treatments were not being utilizes in majority of the terminal diagnosis due to its unavailability. Failing the interventions of modern equipments in terminal diagnosis failed in treating the symptoms effectively in many cases. The higher rates or costly of medical treatments rates and medicines prices becomes the underlying reason for those living under poverty lines failed to undergo proper medical interventions in their cancer experiences, which resulted in experiencing the 
worst and painful life experience for 5-7 years. Moreover, treatments like Breast Conserving Surgery, Mastectomy, Chemotherapy, Radiation Theory, and Scanning related treatments, which were the core treatments to cancer and terminal diagnosis, requires maximum amounts of money that the poor cancer affected people were remained helpless. The quality treatment plan and policy are the core components for successful cancer metastasis diagnosis, which is also visible ineffective to the minimal. The main emphasis of a cancer diagnosis is to cure the symptom of the cancer patient or to prolong the lives' of the patientthrough ensuring quality of life $[15,16,18]$. However, the greatest challenges in the cancer diagnosis in the Northeast region is the ensuring of the patient quality of life, which is not visible in the clinical practices of the country as a whole, and unnecessarily prolonging the patient lives with an aim to increases the numbers of days spend in the hospital ward for more bills. The patient's value and dignity were unconcern the most by the clinicians' and the patient undergoing treatment against their will/choices need to be rectifying immediately in the health care systems of the country as a whole.

The early detection and immediate treatment is the most effective way of cancer diagnosis to control the cancer metastasis and to deliver total cure. The medical intervention in stages one and two has higher possibilities rates to cure, which has around $80 \%$ cure possibilities in any cancer experiences. While detecting the cancer symptom and consulting the oncologists in stage three is visible in curtail conditions, having higher impossibility rates as the cancer metastasis accelerates in higher speeds from one body part to another. However, if the stage three patient being diagnosis by special medical team in a well to do clinical setting, it has around $60 \%$ possibility chances to cure. Though being cure in stage three does not guarantee a complete free from cancerous cells, there is a possibility of being in terminal stage after three to five months, as the cancer cells have the possibility of hiding under another cells that is hard to detect, resulting in leading one's life a disability-adjusted life years (DALY) [15, 16]. Nevertheless, the detection of the cancer symptoms in the fourth stage have no possible ways to cure by any means, which is term as the 'terminal stage' that is $100 \%$ impossible to cure in any clinical practices.
Thus, resulting in leaving the patient with disabilityadjusted life for five to seven years until the inevitable death strikes him/her.

These 5-7 years period of terminal experience is the most crucial moment for every terminal patients, which is also considers as the worst moment in a terminal experience with heartful of emotional sufferings and mindful of mental disharmony that needs special considerations to the most. The acknowledgment of the psycho-emotional symptoms alongside the treatments of physical pain is very essential in any terminal diagnosis in the clinical practices. However, at present India turns out to be the worst place to die or a place not to die. The reasons for unfruitfulness behind the undergoing cancer/terminal diagnosis in the existing cancer care centers in Northeast regions lies in the core emphasis is on the physical pain treatment alone. The psychological symptoms experiences by the cancer/terminal patients, which were produces due to their encounter with cancer were not acknowledge for a symptom that need to be treated in the clinical practices. Thus, failing to acknowledge and leaving the psycho-emotional symptoms untreated resulted in worsening the patient's conditions, and on the other hand, it makes the treatments of the patient physical pain symptom unfruitful due to the patient psychoemotional not in well-being. Well being of the whole body or healthy living requires a psycho-emotional well-being to the most; a psychological well-being can give positive responses to physical pain treatment to the maximum. In India as a whole, the clinicians tend to forgot that even when cure is not possible in terminal diagnosis, there is a possibility of delivering healing as an alternative to cure. However, only through a person centered meaning making psychotherapy in the clinical practices. The psychological self-reflective and life review therapeutic approach in terminal diagnosis can make oneself aware that he/she is still in the condition of limitless achievements. Which will in turn helps the patient to recreate his/her life goals, and set new life goal that could be achieved in a due time, also able to make beautiful memories with his/her loved ones and deliver quality of life. Above all, it will make dying as normal as birth, which will deliver peaceful and meaningful death [19]. Thus, in terminal diagnosis, healing can be delivers as an alternative to cure, even 
when total cure is not possible in the clinical practices. However, sadly, in the clinical practices of the Northeast region and India as a whole, the clinicians alone are the core medical team in the cancer/terminal diagnosis, in the absences of professional clinical psychologists and clinical social workers. The terminal diagnosis requires a multidisciplinary team to deliver quality of life and quality end-of-life care. The clinicians were responsible for treated the physical pain symptoms related, while the clinical psychologists and clinical social workers were responsible for the patient psycho-emotional suffering treatments, which the trained medical doctors or nurses cannot handles in the clinical practices.

\section{CHALLENGES AND CONCLUSION}

Looking at the present conditions of Northeast regions of the country, cancer affected people and its mortality rates is visible rapidly increasing mainly due to people unawareness on the causes of cancerous, treatment policy, unhealthy lifestyles, and unhealthy food consumptions with no proper preventive measures interventions. Moreover, though densely populated with cancer illness, the cancer care centers in the regions are minimal, and some places in these regions are being cut-off from good transportations and communication systems. Thus, majority of the cancer patients in those areas have no choice, but to live with the cancer symptoms with unbearable physical pain and mental disharmony. Majority of the cancer patient in Northeast regions failed to maintain their diets, in which proper dietary is the core for successful diagnosis. The uses of tobacco, cigarettes, bitternuts were visible the common causes of cancer in Northeast India, in which eliminating the usages of tobacco, cigarettes and chewing of bitternuts can successfully reduces the rates of oral lip, breast, mouth, cervical, head and neck, and the nasopharyngeal (NPC) cancer into at least $40-50 \%$ in North East region, as per the researcher findings.

Another urgent need of the regions is to develop social awareness on the causes of cancer, and treatment policies by educating the Northeast people mainly those leaving in the rural areas of the region. Gearing up for health awareness and strengthening the health care team at the community level by addressing the cancer preventive measures in the NE region will effectively decreases the growing cancer populations. It is also important to maximize the numbers of the regional cancer care centers and the government increasing the funding amounts for cancer awareness and treatments in the rural areas. As stated by many researches, the government agencies, nongovernmental organizations and the present media can plays a major in maximizing the level of cancer awareness among the public, especially in the rural undeveloped or uneducated areas. Moreover, those local celebrities and well-known figures involvements in promoting cancer awareness, the awareness effective rates will be visible hugely. Hygienic living by maintaining the surrounding need and clean can helps in controlling the rapid growths of cancer populations in these regions more effectively. The community leaders organizing several seminars on cultural related cancer awareness programs in each community or within the tribes would enhances people understanding on the causes of cancerous related illness, preventive measures, and treatment policies in a better way. On the other hand, the mobile mammography units in Northeast India can effectively reduces several barriers to breast and its related cancers among the Northeast women, if they can set their target to the interior villages and unreached areas. On the other hand, many studies proposes that the present conditions of the mobile mammography in the Northeastern states need to be updates with appropriate equipments and infrastructures, with maintaining quality resources for better functioning in the regions. Since, most of the cancer mortality in India as a whole occurs between 30-69 ages, these ages group need special considerations by the mobile mammography units and other cancer care agencies in Northeast regions. Moreover, the rural undeveloped areas in Northeast states should be the targets of every organizations working in cancer awareness programs, as $80 \%$ of cancer mortality are from the rural areas due to lack of awareness. Thus, at present the main causes of the rapid increasing of cancer in Northeast India are people unawareness of the cancerous symptoms, late detection of the cancerous symptom with late medical interventions, and most importantly lack of cancer treatment centers in the regions. It is high time for the Northeast people to take up necessary steps to fight against the cold-blooded killer, and better late than 
never is the need of the hour. In the battle of cancer/terminal illness fighting back and defending people is the only option that the Northeast people had. For the love of humanity let the terminal diagnosis, acknowledge the psycho-emotional sufferings of the patient alongside the physical pain symptoms to deliver a whole person or total healing treatment in the clinical practices.

\section{Conflict of interest}

The authors disclosed no conflict of interest during the preparation or publication of this manuscript.

\section{Financing}

The authors disclosed that they did not receive any grant during conduction or writing of this study.

\section{REFERENCES}

1. World Health Organization. Global action against cancer 2018. Available http://www.who.int/cancer/media/GlobalActionCancerEnglfull.p df? Accessed 25th September, 2018.

2. Ingole SP, Kakde AU, Bonde PB. A review on statistics of cancer in India. IOSR J Environ Sci Toxicol Food Technol 2016;10:107-16.

3. Singh TT. Cancer scenario in Northeast India. Available at http://www.epao.net/

epsubpageExtractor.asp?src+education.Health_Issue.Scenario_in _Northeast_India. Accessed October 25, $201 \overline{8}$.

$\overline{4}$. NICPR-ICMR. Cancer hits more women in India than men, but more men to die. Available at http://www.nicpr.res.in/images/imp ban.png2017. Accessed December 4, 2018.

5. Deccan Chronicle. (Sept. 12, 2018). Cancer kills 10 million in India. Available at https:/www.deccanchronicle.com/lifestyle/health-and-

wellbeing/120918/cancer-to-kill 10-mn- in-2018 -despite-better-prevention.html Accessed 30th September, 2018. 6. Sreedevi A, Javed R, Dinesh A. Epidemiology of cervical cancer with special focus on India. Int $\mathrm{J}$ Womens Health 2015;7:405-14.

7. NICPR (August 23, 2018). Cancer statistic in India. Available at http://cancerinindia.org.in/statistics/. Accessed 3rd December,
2018.

8. Cherian V. Cancer prevention and control in India. 50 years of cancer control in India 2016. Available at https://mohfw.gov.in/sites/default/files/Cancer $\% 20$

Prevention\%20And\%20Control\%20In\%20India.pdf. (Accessed 27th September, 2018.

9. National Tobacco Control Programme. Manipur has the highest tobacco consumption in India. Retrieved from https:/www.ifp.co.in/page /items/8126/8126-manipur-has-thehighest-tobacco-consumption-in-india/. Accessed 1st November, 2018.

10. Global Adult Tobacco Survey. India 2016-2017/Report.

Available

at http://www.indiaenvironmentportal.org.in/files/file/GATS_.pdf. Accessed 1st November, 2018.

11. Kataki AC, Simons MJ, Das AK, Sharma K, Mehra NK. Nasopharyngeal carcinoma in the Northeastern states of India. Chin J Cancer 2011;30:106-13.

12. Bhattacharjee A, Chakraborty A, Purkaystha P. Prevalence of head and neck cancers in the North East -An Institutional Study. Indian J Otolaryngol Head Neck Surg 2006;58:15-9.

13. Preeet D. Cancer -A Looming Threat In The North East. The Shillong Times. Available at http://www.theshillongtimes.com/2016/07/26/cancer-a-loomingthreat-in-the-north-east/. Acessed 30th October, 2018.

14. Anand P, Kunnumakkara AB, Sundaram C, Harikumar KB, Tharakan ST, Lai OS, et al. Cancer is a preventable disease that requires major lifestyle changes. J Pharm Res 2008;25:2079-116. 15. Dikshit R, Gupta PC, Ramasundarahettige C, Gajalakshmi V, Aleksandrowicz L, Badwe R, et al.; Million Death Study Collaborators. Cancer mortality in India: a nationally representative survey. Lancet 2012;379:1807-16.

16. Murthy NS, Chaudhry K, Nadayil D, Agarwal UK, Saxena S. Changing trends in incidence of breast cancer: Indian scenario. Indian J Cancer 2009;46:73-4.

17. World Health Organization. WHO list of priority medical devices for cancer management: WHO Medical Device Technical Series 2017. Available at http://apps.who.int/iris/bitstream/handle/10665/255262/9789241 565462eng.pdf;jsessiond=4A6BE3B164041D129A49E2F00628 2717? sequence $=1$. Accessed 8th December, 2018.

18. Sharma TD, Sinam N, Singh TT, Devi RP, Sarma R, Bhaumik A, et al. Evaluation of socio-demographic profile of patients with cervical cancer at regional cancer centre in Manipur. Indian J Appl Res 2017;7:701-4.

19. Vaiphei SD, Sisodia DS. Existential psychotherapeutic intervention in the end-of-life and positive outcomesagn: an overview. J Indian Health Psychol 2018;13:20-34. 